\title{
Sleep Disorders and Risk of Motor Vehicle Accident
}

\author{
Soo Hwan Yim ${ }^{1}$, Jae Wook Cho², Jun-Sang Sunwoo ${ }^{3}$, Daeyoung Kim4, Dae Lim Koo ${ }^{5}$, \\ Hee-Jin Im $^{6}$, Hyeyun Kim ${ }^{7}$, Kyung Min Kim ${ }^{8}$, Kwang IK Yang'; \\ On behalf of the Korean Sleep Research Society
}

${ }^{1}$ Department of Neurology, Ulsan University College of Medicine, Gangneung Asan Hospital, Gangneung,

${ }^{2}$ Department of Neurology, Pusan National University Yangsan Hospital, Pusan National University College of Medicine, Yangsan,

${ }^{3}$ Department of Neurosurgery, Seoul National University Hospital, Seoul,

${ }^{4}$ Department of Neurology, Chungnam National University College of Medicine, Chungnam National University Hospital, Daejeon,

${ }^{5}$ Department of Neurology, Seoul Metropolitan Government Seoul National University Boramae Medical Center,

Seoul National University College of Medicine, Seoul,

${ }^{6}$ Department of Neurology, Hallym University Dongtan Sacred Heart Hospital, Hwaseong,

${ }^{7}$ Department of Neurology, International St. Mary's Hospital, Catholic Kwandong University College of Medicine, Incheon,

${ }^{8}$ Department of Neurology, Severance Hospital, Yonsei University College of Medicine, Seoul,

${ }^{9}$ Sleep Disorders Center, Department of Neurology, Soonchunhyang University Cheonan Hospital, Cheonan, Korea

\section{수면장애와 교통사고의 위험}

임수환, 조재욱 ${ }^{2}$, 선우준상 ${ }^{3}$, 김대영 ${ }^{4}$, 구대림 ${ }^{5}$, 임희진 ${ }^{6}$, 김혜윤 $^{7}$, 김경민 $^{8}$, 양광익 ${ }^{9}$ 대한수면연구학회

${ }^{1}$ 울산대학교 의과대학 강릉아산병원 신경과학교실, ${ }^{2}$ 부산대학교 의과대학 양산부산대병원 신경과학교실, ${ }^{3}$ 서울대학교병원 신경외과,

${ }^{4}$ 충남대학교 의과대학 충남대학교병원 신경과학교실, ${ }^{5}$ 서울대학교 의과대학 보라매병원 신경과학교실,

${ }^{6}$ 한림대학교 의과대학 동탄성심병원 신경과학교실, ${ }^{7}$ 가톨릭관동대학교 의과대학 국제성모병원 신경과학교실,

${ }^{8}$ 연세대학교 의과대학 세브란스병원 신경과학교실, ${ }^{9}$ 순천향대학교 의과대학 천안병원 수면장애센터 신경과학교실

\section{Received August 3, 2021 \\ Revised August 23, 2021 \\ Accepted August 25, 2021}

Address for correspondence Kwang IK Yang, MD, PhD Sleep Disorders Center,

Department of Neurology,

Soonchunhyang University

Cheonan Hospital,

31 Soonchunhyang 6-gil,

Dongnam-gu,

Cheonan 31151, Korea

Tel: +82-41-570-2290

Fax: +82-41-592-3810

E-mail: neurofan@schmc.ac.kr
Driving is a complicated process that demands coordination between a range of neurocognitive functions, including attention, visuo-perception, and appropriate judgment, as well as sensory and motor responses. Therefore, several factors may reduce the driving performance of an individual, such as sleepiness, distraction, overspeeding, alcohol consumption, and sedative drugs, all of which increase the hazard of motor vehicle accidents. Among them, drowsy driving is a major cause of traffic accidents, leading to more serious injuries as compared to other causes of major traffic accidents. Although sleep disorders have been highly associated among drowsy drivers, they are often untreated and unrecognized as a disease. In particular, obstructive sleep apnea and narcolepsy are some sleep disorders that are highly related to traffic accidents. Insomnia, which can cause inadequate sleep duration and promote sedative effects from sleeping pills, may also cause traffic accidents. These conditions are especially applicable to commercial bus or truck drivers, nocturnal workers, and shift workers, who are highly vulnerable to drowsy driving. Therefore, assertive screening and management of sleep disorders are necessary in general private drivers and relevant occupational drivers.

J Sleep Med 2021;18(2):72-77

\section{서 론}

2017년 7월 9일 경부고속도로 양재나들목 인근에서 대형

This is an Open Access article distributed under the terms of the Creative Commons Attribution Non-Commercial License (https://creativecommons.org/licenses/by-nc/4.0) which permits unrestricted non-commercial use, distribution, and reproduction in any medium, provided the original work is properly cited.
버스를 운전하던 기사의 졸음운전(drowsy driving)으로 8중 추돌사고가 발생하였다. ${ }^{1}$ 이 사고로 버스가 들이받은 승용차 에 있던 승객 2명이 안타깝게 모두 현장에서 사망하였다. 당 시 사고현장에는 스키드마크(skid marks)는 없었다. 해당 버 스 운전자는 경찰조사에서 졸음운전을 했다고 진술하였다. 이 사고는 찰나의 졸음운전이라도 엄청난 인명피해를 가져 
올 수 있다는 것을 보여주는 예시이다.

운전은 시각지각능력 뿐만 아니라, 주의력, 의사결정능력 과 같은 다양한 신경인지 기능과 감각 및 운동기능 간의 협응 이 필요한 복잡한 절차이다. ${ }^{2,3}$ 때문에 졸림(sleepiness), 주시 태만, 음주운전 그리고 약물복용상태 등 주의력결핍상태에 서 운전을 하는 행위는 교통사고의 위험성을 높인다. ${ }^{4}$ 특히 졸음운전은 교통사고 발생과 관련된 가장 중요한 인자이다. ${ }^{5}$

교통사고는 국내 10대 사망 원인 중 하나이다. ${ }^{6}$ 교통사고 발생원인 중 졸음운전은 사고 발생 시 사망과 손상의 위험을 더 높인다. ${ }^{78}$ 한국도로공사에 따르면 2015-2019년에 발생한 교통사고 중에서 사망사고는 1,079 건이었다. 사고발생 원인 첫번째는 졸음운전 및 주시태만이었으며 그 비중은 $67.6 \%$ (726명)였다. ${ }^{9}$ 두번째인 과속으로 인한 교통사고가 128명 (11.9\%)인 것을 감안하면 졸음운전 교통사고의 사망률은 매우 높다. 이전 연구에서 보고된 바에 의하면 졸음운전 교통사고 의 위험군은 첫째 적절한 수면시간이 부족한 운전자, 둘째 장거리 운전자, 셋째 수면질환이 있는 운전자이다. ${ }^{10,11}$ 국내 19세 이상 일반 성인 1,675 명을 대상으로 한 설문조사에서 $23.6 \%$ 가 졸음운전 경험이 있었고 그 중 $33.1 \%$ 에서는 적어도 한달 에 한 번 이상 졸음운전을 경험하였다. ${ }^{12}$ 또한, 24 세에서 65 세 사이 성인 1,111 명(사업용 운전자 110 명, 일반 1,001 명)을 대 상으로 한 수면습관 및 수면장애에 대한 설문조사에서 사업 용 운전자가 비사업용 운전자에 비해 고위험 폐쇄수면무호 흡, 불면심각도지표(Insomnia Severity Index, ISI), 주간졸 림지수, 우울지수가 높았다. ${ }^{13}$

졸림은 정상 생리현상이기도 하지만 수면장애에서 나타나 는 흔한 증상 중의 하나이다. 운전자의 평소 수면습관 및 수 면장애를 포함한 수면건강을 적극적으로 관리한다면 졸음 운전으로 인한 교통사고를 줄이거나 예방할 수 있기 때문에 운전자의 졸림에 대한 사회적 관심이 필요하다. 본 종설에서 는 수면부족 및 국제수면장애분류 3판(International Classification of Sleep Disorders-3rd edition, ICSD-3) ${ }^{14}$ 에 근거 한 수면장애분류를 이용하여 불면증(insomnia), 수면관련호 흡장애(sleep related breathing disorders), 과다졸림의 중추 장애(central disorders of hypersomnolence), 하루주기리듬 수면장애(circadian rhythm sleep-wake disorders), 사건수면 (parasomnia) 및 수면관련이상운동(sleep related movement disorders) 등과 교통사고의 연관성을 알아보고자 한다.

\section{본 론}

\section{수면부족과 교통사고}

비사업용 운전자 4,097명을 대상으로 한 수면시간과 교통
사고에 관한 설문조사에 의하면 주중에 7-8시간 수면을 취 하는 운전자들에 비하여 6-7시간 수면을 취하는 운전자는 6.3배, 6시간 미만 수면을 취하는 운전자는 교통사고 발생률 이 8 배 더 높게 나타났다. ${ }^{15}$ 또한, 최근 보고된 메타분석에 의 하면 운전 중 졸림을 경험했던 운전자는 그렇지 않은 운전 자보다 교통사고 발생률이 2.5 배 더 높았다. ${ }^{5}$ 40세 이상 성인 3,201 명을 대상으로 한 설문조사에 따르면 지난 1년 동안 적 어도 1 회 이상 교통사고가 발생한 운전자의 수면시간(6.9시 간)이 교통사고가 없었던 운전자의 수면시간(7.1시간)에 비 하여 적은 것으로 나타났다. 특히, 6시간 미만으로 수면을 취 하는 운전자는 7-8시간 수면을 취하는 운전자에 비하여 교 통사고 발생이 $33 \%$ 이상 증가했다. ${ }^{16}$ 국내 20 세 이상 성인(평 균 43.2세)을 대상으로 한 설문조사에서도 수면시간이 부족 하다고 생각하는 운전자는 수면시간이 충분하다고 생각하 는 운전자보다 졸음운전 경험이 1.35 배 더 많았다. ${ }^{12}$ 또한, 평 소 1 주일에 2 회 이상 음주를 하는 경우라도 충분한 수면시 간을 취하는 운전자에서는 졸음운전 경험과 관련이 없었지 만, 불충분한 수면시간을 호소하는 운전자에서는 졸음운전 경험이 2.17배 더 높았다. ${ }^{12}$ 기저수면질환이 없는 17-24세의 젊은 연령층에서도 6시간 미만 수면시간을 취할 경우 6시간 이상 수면시간을 취하는 운전자와 비교하여 교통사고 발생 률이 1.21 배 더 높게 나타났다. 특히, 주말 수면시간이 6시간 미만일 경우 교통사고 발생률이 1.55 배 더 높았다. ${ }^{17}$ 운전자 의 수면시간과 수면만족도는 나이와 음주습관에 상관없이 졸음운전 교통사고 발생에 영향을 줄 수 있다. 국내 사업용 운전자 연구에서도 수면이 부족하다고 생각하는 운전자가 수면이 충분하다고 생각하는 운전자보다 졸음운전 아차사 고(near-miss accidents) 발생률이 3.06배 높았으며, 연속운전 시간 $(>4$ 시간)이 긴 사업용 운전자는 연속운전시간 $(<2$ 시 간)이 짧은 운전자보다 졸음운전 아차사고 발생률이 3.10 배 더 높았다. ${ }^{18}$

\section{불면증과 교통사고}

불면증은 성인의 약 $22 \%-30 \%$ 에 영향을 미치는 흔한 수면질 환이다. ${ }^{19,20}$ 불면증 증상이 있는 성인은 약 $30 \%-40 \%$ 이다. ${ }^{21-23}$ 불면증은 주간졸림과 피로감, 신경운동결손, 인지기능저하 를 흔하게 일으킨다. 사업용 운전자를 대상으로 한 불면증 유병률 조사에 따르면 $15.2 \%$ 에서 불면증이 동반되었다. ${ }^{13}$ 이 러한 결과는 비사업용 운전자의 불면증 유병률 $4.1 \%$ 보다 높 은 수치이다. 불면증을 동반한 사업용 운전자는 비사업용 운 전자와 비교하여 졸음운전 발생률이 높았다. 장시간 운전을 하는 사업용 운전자를 대상으로 한 연구에서 폐쇄수면무호 흡(obstructive sleep apnea), 주간졸림, 짧은 수면시간 및 다 
른 동반질환들을 보정한 경우라도 불면증이 있는 운전자의 경우 교통사고의 발생률이 불면증이 없는 운전자에 비해 1.82 배 더 높게 나타났다. 불면증을 동반한 운전자는 아차사 고에 대한 발생률도 3.35 배나 더 높았다. ${ }^{24}$

비사업용 운전자를 대상으로 한 졸음운전 경험 여부에 대 한 연구에서는 불면심각도지표가 졸음운전을 경험한 군은 ISI 4.7, 그렇지 않은 군은 ISI 4.1로 경미한 차이를 보였다. ${ }^{12}$

불면증 환자에게 약물은 교통사고를 발생시키는 위험요소 로 작용할 수 있다. ${ }^{25}$ 프랑스에서 2005-2008년에 발생한 교 통사고와 연관된 72,658 명의 운전자 중에 벤조디아제핀 성분 약물을 복용하고 있던 운전자의 경우 교통사고 발생률은 약 물을 복용하지 않았던 운전자에 비해 1.39 배 더 높게 나타났 다. 또한, 사고 5 개월 전부터 하루 한 알 이상 졸피뎀을 복용 하고 있던 운전자는 그렇지 않은 운전자에 비해 교통사고 발 생률이 2.46배 더 높게 나타났다. ${ }^{26}$

이처럼 약물로 인한 교통사고 위험이 우려되는 경우에는 저용량의 약물 및 반감기가 비교적 짧은 약물을 처방해야 한 다. 또한 다음날 운전을 하는 경우 약물을 일찍 복용하도록 지도해야 한다.

\section{수면관련호흡장애와 교통사고}

수면관련호흡장애의 대표적 질환인 폐쇄수면무호흡은 반 복되는 야간의 저산소증, 수면분절 등으로 주간졸림을 유발 하여 운전시 집중도를 저하시킨다. ${ }^{27}$ 메타분석으로 확인된 폐쇄수면무호흡 운전자의 교통사고 발생률은 그렇지 않은 운전자에 비해 2.52배 더 높다. ${ }^{28}$ 폐쇄수면무호흡을 동반한 운전자들 중 엡워스졸림척도(Epworth Sleepiness Scale, ESS) 가 10 미만이거나, 무호흡-저호흡지수(apnea-hyponea index, $\mathrm{AHI}$ 가 40 이하인 경우가 교통사고 발생과 뚜렷한 연관이 있었다. ${ }^{29}$

호주 사업용 운전자 대상 교통사고 발생 연구에서 지난 3년 동안 발생한 교통사고가 폐쇄수면무호흡을 동반한 운전자가 그렇지 않은 운전자에 비해 1.3 배 더 높게 확인되었다. 주간 졸림정도(ESS $>18)$ 가 상위 $5 \%$ 이내의 운전자는 교통사고 발생이 일반 운전자에 비해 1.91 배 더 높았으며, 교통사고가 2 회 이상 발생하는 경우도 2.67 배 더 높았다. ${ }^{30}$ 터키의 사업용 운전자 280명(고위험 폐쇄수면무호흡, 30명; 저위험 폐쇄수 면무호흡, 250명)을 대상으로 시뮬레이션 운전검사에서 초 기반응시간검사를 시행한 결과 저위험 폐쇄수면무호흡군의 실패율은 $28 \%$ 로 낮았으나, 고위험 폐쇄수면무호흡을 동반 한 운전자의 실패율은 $47 \%$ 로 저위험 폐쇄수면무호흡군보다 높았다. ${ }^{31}$ 이러한 결과는 폐쇄수면무호흡의 정도가 심할수록 주간졸림뿐만 아니라 운전 중 신속한 반응속도를 저하시켜
서 교통사고를 일으킨다는 것을 시사한다.

국내 사업용 운전자를 대상으로 한 조사에 따르면 $35.5 \%$ 에서 고위험 폐쇄수면무호흡이 동반되었다. ${ }^{13}$ 이러한 결과는 비사업용 운전자에서 나타나는 고위험 폐쇄수면무호흡의 유 병률 $12.2 \%$ 와 비교하면 아주 높은 수치이며 다른 위험변수 (나이, 체질량지수, 알코올 섭취 등)를 보정해도 일반운전자 보다 3.68배 더 높게 나타났다.

하지만, 심한 폐쇄수면무호흡을 동반한 운전자라도 적극 적으로 비강지속기도양압(nasal continuous positive airway pressure, nasal CPAP)을 적용하면 치료시작 2-7일 이내로 주간졸림이 크게 개선되며 교통사고의 발생률도 낮출 수 있 다. ${ }^{32}$ 중등도 이상의 폐쇄수면무호흡(AHI> 25)을 동반한 운 전자도 꾸준하게 비강지속기도양압을 적용하면 일반 성인 의 교통사고 발생률 수준까지 저하된다. ${ }^{33}$

이와 같이 국내 사업용 운전자의 수면건강상태는 비사업 용 운전자에 비해 좋지 않아 졸음운전 교통사고 발생 위험에 노출되기 쉽다. 또한 사업용 운전자는 대형트럭이나 대형버 스를 운전하는 경우가 많아 대형사고로 이어질 위험이 크다. 국내 사업용 운전자(161명)의 설문조사에 따르면 장시간 운 전(>12시간/일)을 하거나, 주간졸림(ESS $>10)$ 이 동반되는 경우 지속적인 난폭운전을 하는 경우가 많다. ${ }^{34}$ 사업용 운전 자의 졸음운전 교통사고 위험에 대한 회사의 근무여건개선 및 국가적인 제도마련이 필요하다.

\section{과다졸림의 중추장애와 교통사고}

기면병(narcolepsy)은 주간졸림과 밀접한 연관이 있는 수 면질환이다. 기면병 환자는 반복적으로 억누를 수 없는 수면 욕구를 느끼거나 잠에 빠져든다. 기면병의 졸림은 적극적인 활동이 필요없는 단조로운 상황에서 가장 흔하게 발생한다. ${ }^{35}$ 기면병은 운전 시 감정적인 자극에 의하여 유발되는 탈력발 작이 발생할 가능성이 있다. 일반적으로 기면병의 졸림은 폐 쇄수면무호흡의 졸림보다 횔씬 참을 수 없다. ${ }^{36}$ 일반 성인과 기면병 환자를 대상으로 5 년 동안 추적 관찰한 결과에서 일 반 성인에서 졸음운전 교통사고가 발생할 확률은 약 $5 \%$ 이지 만, 치료받지 않는 기면병 환자는 약 50\%에서 졸음운전 교 통사고가 발생하였다. ${ }^{37}$ 또한, 중추졸림과다 기면병 1형, 기 면병 2형, 그리고 특발수면과다증 세가지군으로 구분하여 지난 5년 동안 교통사고 및 아차사고의 경험을 조사한 결과 세군 모두에서 $50 \%$ 이상의 사고 발생을 경험하였다. 특히, 탈력발작이 동반되는 기면병 1형의 경우 $75 \%$ 에서 교통사고 가 발생했다. 또한 주간졸림(ESS $\geq 16)$ 이 심할수록 사고 발 생이 높았다. ${ }^{38}$ 


\section{하루주기리듬수면장애와 교통사고}

야간근무와 교대근무는 불규칙한 수면시간으로 하루주기 리듬수면장애의 비동조화를 일으켜서 하루주기리듬수면장 애를 야기시킨다. 한국보건사회연구에서 조사한 2019년 자료 에 따르면 전체 근로자 중 남성의 $14.4 \%$, 여성의 $11.6 \%$ 가 교 대근무자이다. ${ }^{39}$ 또한 고용노동부에서 조사한 전체 근로자의 $10.2 \%-14.5 \%$ 인 127-197만명이 야간근로자로 추정된다. ${ }^{40}$ 미국 야간교대근로자 2,570명을 대상으로 한 설문조사에서 약 36\%-45\%가 참을 수 없는 주간졸림을 호소하는 것으로 보고되었다. ${ }^{41}$ 이와 같이 야간근무와 교대근무처럼 불규칙적 인 근무시간으로 하루주기리듬수면장애의 위험에 노출된 인구비중은 매우 크다.

국내 버스운전자 332명을 대상으로 시행한 설문조사에서 야간에 일하는 운전자는 주간에만 일하는 운전자에 비해 심 한 주간졸림과 운전 중 심한 졸림을 호소하였다. 알코올 섭취, 버스운전경력, 수면시간을 보정하고도 야간근무자의 운전 중 심한 졸림의 위험비(risk ratio)는 주간운전자보다 5.71배 더 높게 나타났다. ${ }^{42}$

일본 대중교통운전자의 주간졸림( $\mathrm{ESS} \geq 11)$ 중 가장 큰 원 인은 일반적으로 나타나는 폐쇄수면무호흡이 아닌 하루주기 리듬수면장애였다. ${ }^{43}$ 야간교대운전자 졸림정도(ESS 13.17) 도 폐쇄수면무호흡(ESS 7.73)에 의한 것보다 더 심한 것으로 나타났다. ${ }^{44}$

야간교대근무는 무호흡-저호흡지수를 더욱 악화시키는 경향이 있다. ${ }^{45}$ 교대근무자가 폐쇄수면무호흡이 동반될 경우 더욱 심한 주간졸림을 유발하여 교통사고의 발생위험을 높 인다.

\section{사건수면 및 수면관련이상운동과 교통사고}

성인몽유병 및 성인야경증은 소아에 비하여 그 유병률이 적으며 증상의 강도도 소아에 비하여 경하다. ${ }^{46,47}$ 성인몽유병 및 야경증 환자를 대상으로 졸음운전 교통사고의 발생위험 을 연구한 사례는 아직 없다. 다만, 이런 환자에서는 졸음운 전에 영향을 줄 수 있는 주간졸림(ESS $>10)$ 증상이 정상군 에 비해 높게 나타났다. ${ }^{48}$

여러 연구에서 수면중주기사지운동(periodic limb movements in sleep)이 주간졸림을 유발한다는 보고는 없다. ${ }^{49-51}$ 주기사지운동장애(periodic limb movement disorder)의 주 간졸림에 대해 기면병, 폐쇄수면무호흡, 불면증과 그 정도를 비교한 연구가 있다. ${ }^{52}$ 해당 연구에서 주기사지운동장애의 주간졸림은 ESS 8.30 (95\% confidence interval [CI], 2.7813.82)으로 불면증 ESS 7.14 (95\% CI, 2.33-11.95)보다는 높 은 수치로 확인되나, 기면병 ESS 17.04 (95\% CI, 12.47-
21.61)와 폐쇄수면무호흡 ESS 11.10 (95\% CI, 6.35-16.35)보 다는 낮게 나타난다.

하지불안증후군(restless leg syndrome)은 하지에 간헐적 인 불편감으로 수면효율을 감소시켜 삶의 질을 저하시킨 다. ${ }^{53}$ 주간졸림과 하지불안증후군 간에 직접적인 인과관계 혹은 연관성에 대해 확인된 연구나 보고는 아직까지 없다. 수면중주기사지운동, 주기사지운동장애, 그리고 하지불안증 후군 등과 같은 수면관련이상운동과 졸음운전 교통사고의 연관성에 대해서는 아직 명확하지 않다.

\section{결 론}

졸음운전 교통사고는 과속, 주시태만 등 운전자의 과실이 주요 원인인 사고유형과 달리, 예방과 치료가 가능한 원인이 라는 점에서 타 사고유형과 차별화된 접근이 필요하다. 졸음 운전 교통사고를 줄이기 위해 위험구간 안내방송 및 졸음쉼 터 설치, 졸림 방지를 위한 자동차 시스템의 개발 등 다양한 방법을 개발하고 있다. 졸림이란 정상 생리현상일 수 있지만, 다양한 수면장애라는 의학적 원인에 의해 발생하는 병리 현 상일 수 있다. 정상 생리현상이라 하더라도 졸림은 교통사고 의 위험성을 증가시킨다. 때문에 졸림에 대한 의학적 접근을 통한 원인 분석과 적절한 대책이 졸음운전 교통사고를 예방 할 수 있을 것이다. 본론에서 말한 바와 같이 평소 수면이 부 족한 운전자, 기면병 및 폐쇄수면무호흡이 있는 운전자, 야간 및 교대근무자가 졸음운전 교통사고의 위험성이 높다.

졸음운전 교통사고 방지를 위해서는 개인의 노력 뿐만 아 니라 사회적 제도개선이 함께 뒷받침되어야 한다. 1) 졸음운 전으로 인한 사고는 개인의 수면부족 및 수면장애가 원인이 될 수 있기 때문에 장거리 운전이 계획되어 있거나, 평소 자 주 운전을 하는 운전자라면, 스스로 규칙적인 시간에 잠들고 일어나며 충분한 수면시간을 갖도록 한다. 2) 충분히 잠을 자 는 데도 불구하고 운전시 주간졸림이 지속된다면 수면장애 에 대한 진단 및 치료가 필요하다. 3) 비사업용 운전자에 비 해 주간졸림에 취약한 사업용 운전자를 위해서 근무환경을 개선해야 한다. 연속 운전시간 제한 및 운전 중 휴식을 할 수 있도록 회사 및 공적 제도 마련이 동시에 이뤄져야 할 것이 다. 본 학술지의 다음 호 종설에서는 폐쇄수면무호흡 및 기면 병을 동반한 운전자 및 교대근무자에서 졸음운전 교통사고 방지를 위한 구체적인 가이드라인을 제시할 것이다.

\section{Conflicts of Interest}

The authors have no potential conflicts of interest to disclose. 


\section{ORCID iDs}

Soo Hwan Yim Jae Wook Cho Jun-Sang Sunwoo Daeyoung Kim

Dae Lim Koo

Hee-Jin Im

Hyeyun Kim

Kyung Min Kim

Kwang IK Yang

https://orcid.org/0000-0003-2948-9244 https://orcid.org/0000-0002-2742-9136 https://orcid.org/0000-0001-8834-0568 https://orcid.org/0000-0001-9056-0017 https://orcid.org/0000-0001-6858-6093 https://orcid.org/0000-0002-8979-6521 https://orcid.org/0000-0002-8008-5539 https://orcid.org/0000-0002-0261-1687 https://orcid.org/0000-0001-6343-6520

\section{Author Contributions}

Conceptualization: Soo Hwan Yim, Kwang IK Yang. Data curation: Daeyoung Kim. Formal analysis: Hee-Jin Im, Hyeyun Kim. Funding acquisition: Dae Lim Koo. Investigation: Daeyoung Kim, Dae Lim Koo. Methodology: Jae Wook Cho, Jun-Sang Sunwoo. Project administration: Jun-Sang Sunwoo. Resources: Hee-Jin Im, Hyeyun Kim. Software: Daeyoung Kim. Supervision: Jae Wook Cho, Dae Lim Koo, Kwang IK Yang. Validation: Soo Hwan Yim, Kwang IK Yang. Visualization: Soo Hwan Yim, Kyung Min Kim. Writing—original draft: Soo Hwan Yim. Writing-review \& editing: all authors.

\section{Funding Statement}

None.

\section{REFERENCES}

1. Chae HS. Sawing the black box video of the 8-fold collision on the Gyeongbu Expressway [Internet News]. Seoul: JoongAng Ilbo $2017 \mathrm{Jul}$ 9 [cited 2021 Jun 15]. Available from: https://news.joins.com/article/21741572.

2. Spiers HJ, Maguire EA. A navigational guidance system in the human brain. Hippocampus 2007;17:618-626. https://doi.org/10.1002/hipo.20298.

3. Spiers HJ, Maguire EA. Neural substrates of driving behaviour. Neuroimage 2007;36:245-255. https://doi.org/10.1016/j.neuroimage.2007.02.032.

4. World Health Organization. World report on road traffic injury prevention [Internet]. Geneva: World Health Organization 2004 [cited 2021 Jun 10]. Available from: http://www.who.int/violence_injury_ prevention/publications/road_traffic/world_report/en/.

5. Bioulac S, Micoulaud-Franchi JA, Arnaud M, et al. Risk of motor vehicle accidents related to sleepiness at the wheel: a systematic review and meta-analysis. Sleep 2017;40:zsx134. https://doi.org/10.1093/sleep/ zsx134.

6. Statistics Korea. Annual report on the causes of death statistics 2017 [Internet]. Daejeon: Statistics Korea 2018 [cited 2021 Jun 18]. Available from: http://kostat.go.kr/portal/korea/kor_nw/1/6/2/index.board.

7. Tefft BC. Prevalence of motor vehicle crashes involving drowsy drivers, United States, 2009-2013 (Technical Report) [Internet]. Washington, DC: AAA Foundation for Traffic Safety 2014 [cited 2021 Jun 20]. Available from: https://aaafoundation.org/wp-content/uploads/2017/12/ PrevalenceofMVCDrowsyDriversReport.pdf.

8. National Highway Traffic Safety Administration. Traffic safety facts crash - stats: drowsy driving [Internet]. Washington, DC: NHTSA's National Center for Statistics and Analysis [cited 2021 Jun 25]. Available from: https://crashstats.nhtsa.dot.gov/Api/Public/ViewPublication/811449.

9. Lee KW. Korea Express Corporation conducted a joint campaign with related organizations to prevent traffic accidents during the holiday season [Internet News]. Seoul: Kukto Ilbo 2020 Jul 24 [cited 2021 June 25]. Available from: https://www.ikld.kr/news/articleView.html?idxno=221331.

10. Stutts JC, Wilkins JW, Scott Osberg J, Vaughn BV. Driver risk factors for sleep-related crashes. Accid Anal Prev 2003;35:321-331. https://doi. org/10.1016/s0001-4575(02)00007-6.

11. McCartt AT, Rohrbaugh JW, Hammer MC, Fuller SZ. Factors associated with falling asleep at the wheel among long-distance truck driv- ers. Accid Anal Prev 2000;32:493-504. https://doi.org/10.1016/s00014575(99)00067-6.

12. Sunwoo JS, Hwangbo Y, Kim WJ, Chu MK, Yun CH, Yang KI. Sleep characteristics associated with drowsy driving. Sleep Med 2017;40:410. https://doi.org/10.1016/j.sleep.2017.08.020.

13. Sunwoo JS, Shin DS, Hwangbo Y, et al. High risk of obstructive sleep apnea, insomnia, and daytime sleepiness among commercial motor vehicle drivers. Sleep Breath 2019;23:979-985. https://doi.org/10.1007/ s11325-019-01805-7.

14. Sateia MJ. International classification of sleep disorders-third edition: highlights and modifications. Chest 2014;146:1387-1394. https://doi. org/10.1378/chest.14-0970.

15. Abe T, Komada Y, Asaoka S, Ozaki A, Inoue Y. Questionnaire-based evidence of association between sleepiness while driving and motor vehicle crashes that are subjectively not caused by falling asleep. Sleep Biol Rhythms 2011;9:134-143. https://doi.org/10.1111/j.1479-8425. 2011.00498.x.

16. Gottlieb DJ, Ellenbogen JM, Bianchi MT, Czeisler CA. Sleep deficiency and motor vehicle crash risk in the general population: a prospective cohort study. BMC Med 2018;16:44. https://doi.org/10.1186/s12916018-1025-7.

17. Martiniuk AL, Senserrick T, Lo S, et al. Sleep-deprived young drivers and the risk for crash: the DRIVE prospective cohort study. JAMA Pediatr 2013;167:647-655. https://doi.org/10.1001/jamapediatrics.2013.1429.

18. Kim D, Shin DS, Lee SC, et al. Sleep status and the risk factor of drowsy-related accidents in commercial motor vehicle drivers. Sleep Med Res 2018;9:97-103. https://doi.org/10.17241/smr.2018.00283.

19. Roth T. Insomnia: definition, prevalence, etiology, and consequences. $J$ Clin Sleep Med 2007;3:S7-S10.

20. Cho YW, Shin WC, Yun CH, Hong SB, Kim J, Earley CJ. Epidemiology of insomnia in Korean adults: prevalence and associated factors. J Clin Neurol 2009;5:20-23. https://doi.org/10.3988/jcn.2009.5.1.20.

21. Hoffmann G. Evaluation of severe insomnia in the general population-implications for the management of insomnia: focus on results from Belgium. J Psychopharmacol 1999;13:S31-S32. https://doi.org/10.1177/ $026988119901304 \mathrm{~S} 08$.

22. Ohayon MM. Epidemiology of insomnia: what we know and what we still need to learn. Sleep Med Rev 2002;6:97-111. https://doi.org/10.1053/ smrv.2002.0186.

23. Ohayon MM, Zulley J, Guilleminault C, Smirne S, Priest RG. How age and daytime activities are related to insomnia in the general population: consequences for older people. J Am Geriatr Soc 2001;49:360-366. https://doi.org/10.1046/j.1532-5415.2001.49077.x.

24. Garbarino S, Magnavita N, Guglielmi O, et al. Insomnia is associated with road accidents. Further evidence from a study on truck drivers. PLoS One 2017;12:e0187256. https://doi.org/10.1371/journal.pone. 0187256.

25. Elvik R. Risk of road accident associated with the use of drugs: a systematic review and meta-analysis of evidence from epidemiological studies. Accid Anal Prev 2013;60:254-267. https://doi.org/10.1016/j. aap.2012.06.017.

26. Orriols L, Philip P, Moore N, et al. Benzodiazepine-like hypnotics and the associated risk of road traffic accidents. Clin Pharmacol Ther 2011; 89:595-601. https://doi.org/10.1038/clpt.2011.3.

27. George CF. Sleep apnea, alertness, and motor vehicle crashes. Am J Respir Crit Care Med 2007;176:954-956. https://doi.org/10.1164/rccm.200605629P.

28. Sassani A, Findley LJ, Kryger M, Goldlust E, George C, Davidson TM. Reducing motor-vehicle collisions, costs, and fatalities by treating obstructive sleep apnea syndrome. Sleep 2004;27:453-458. https://doi. org/10.1093/sleep/27.3.453.

29. Komada Y, Nishida Y, Namba K, Abe T, Tsuiki S, Inoue Y. Elevated risk of motor vehicle accident for male drivers with obstructive sleep apnea syndrome in the Tokyo metropolitan area. Tohoku J Exp Med 2009;219:11-16. https://doi.org/10.1620/tjem.219.11. 
30. Howard ME, Desai AV, Grunstein RR, et al. Sleepiness, sleep-disordered breathing, and accident risk factors in commercial vehicle drivers. Am J Respir Crit Care Med 2004;170:1014-1021. https://doi.org/10.1164/ rccm.200312-1782OC.

31. Demirdöğen Çetinoğlu E, Görek Dilektaşlı A, Demir NA, et al. The relationship between driving simulation performance and obstructive sleep apnoea risk, daytime sleepiness, obesity and road traffic accident history of commercial drivers in Turkey. Sleep Breath 2015;19:865-872. https://doi.org/10.1007/s11325-014-1114-6.

32. Tregear S, Reston J, Schoelles K, Phillips B. Continuous positive airway pressure reduces risk of motor vehicle crash among drivers with obstructive sleep apnea: systematic review and meta-analysis. Sleep 2010;33:1373-1380. https://doi.org/10.1093/sleep/33.10.1373.

33. George CF. Reduction in motor vehicle collisions following treatment of sleep apnoea with nasal CPAP. Thorax 2001;56:508-512. https://doi. org/10.1136/thorax.56.7.508.

34. Kwon S, Kim H, Kim GS, Cho E. Fatigue and poor sleep are associated with driving risk among Korean occupational drivers. J Transp Health 2019;14:100572. https://doi.org/10.1016/j.jth.2019.100572.

35. American Academy of Sleep Medicine. International classification of sleep disorders. 3rd ed. Darien: American Academy of Sleep Medicine, 2014;132-140.

36. George CF, Boudreau AC, Smiley A. Comparison of simulated driving performance in narcolepsy and sleep apnea patients. Sleep 1996;19:711717. https://doi.org/10.1093/sleep/19.9.711.

37. Aldrich MS. Automobile accidents in patients with sleep disorders. Sleep 1989;12:487-494. https://doi.org/10.1093/sleep/12.6.487.

38. Ozaki A, Inoue Y, Nakajima T, et al. Health-related quality of life among drug-naïve patients with narcolepsy with cataplexy, narcolepsy without cataplexy, and idiopathic hypersomnia without long sleep time. J Clin Sleep Med 2008;4:572-578. https://doi.org/10.5664/jcsm.27352.

39. Jung Y. Effects of overwork on health and disease burden. Health-Welfare Issue \& Focus 2019;(362):1-8. Available from: https://www.kihasa. re.kr/publish/regular/focus/view?seq=25060\&page $=5$.

40. Ministry of Employment and Labor. Explanation (Q\&A) and guidelines for special health checkups for night work [Internet]. Sejong: Ministry of Employment and Labor 2014 [cited 2021 Jun 25]. Available from: http://www.moel.go.kr/news/notice/noticeView.do?bbs_ seq $=1389170242858$.

41. Drake CL, Roehrs T, Richardson G, Walsh JK, Roth T. Shift work sleep disorder: prevalence and consequences beyond that of symptomatic day workers. Sleep 2004;27:1453-1462. https://doi.org/10.1093/sleep/
27.8.1453.

42. Lee S, Kim HR, Byun J, Jang T. Sleepiness while driving and shiftwork patterns among Korean bus drivers. Ann Occup Environ Med 2017;29: 48. https://doi.org/10.1186/s40557-017-0203-y.

43. Komada Y, Asaoka S, Abe T, Inoue Y. Short sleep duration, sleep disorders, and traffic accidents. IATSS Res 2013;37:1-7. https://doi.org/10.1016/ j.iatssr.2013.06.001.

44. Asaoka S, Namba K, Tsuiki S, Komada Y, Inoue Y. Excessive daytime sleepiness among Japanese public transportation drivers engaged in shiftwork. J Occup Environ Med 2010;52:813-818. https://doi.org/10.1097/ JOM.0b013e3181ea5a67.

45. Laudencka A, Klawe JJ, Tafil-Klawe M, Złomańczuk P. Does nightshift work induce apnea events in obstructive sleep apnea patients? $J$ Physiol Pharmacol 2007;58 Suppl 5:345-347.

46. Zadra A, Desautels A, Petit D, Montplaisir J. Somnambulism: clinical aspects and pathophysiological hypotheses. Lancet Neurol 2013;12:285294. https://doi.org/10.1016/S1474-4422(12)70322-8.

47. Guilleminault C, Palombini L, Pelayo R, Chervin RD. Sleepwalking and sleep terrors in prepubertal children: what triggers them? Pediatrics 2003;111:e17-e25. https://doi.org/10.1542/peds.111.1.e17.

48. Lopez R, Jaussent I, Dauvilliers Y. Objective daytime sleepiness in patients with somnambulism or sleep terrors. Neurology 2014;83:20702076. https://doi.org/10.1212/WNL.0000000000001019.

49. Al-Alawi A, Mulgrew A, Tench E, Ryan CF. Prevalence, risk factors and impact on daytime sleepiness and hypertension of periodic leg movements with arousals in patients with obstructive sleep apnea. J Clin Sleep Med 2006;2:281-287. https://doi.org/10.5664/jcsm.26587.

50. Leary EB, Moore HE 4th, Schneider LD, Finn LA, Peppard PE, Mignot E. Periodic limb movements in sleep: prevalence and associated sleepiness in the Wisconsin Sleep Cohort. Clin Neurophysiol 2018;129: 2306-2314. https://doi.org/10.1016/j.clinph.2018.08.022.

51. Haba-Rubio J, Marti-Soler H, Tobback N, et al. Clinical significance of periodic limb movements during sleep: the HypnoLaus study. Sleep Med 2018;41:45-50. https://doi.org/10.1016/j.sleep.2017.09.014.

52. Moller HJ, Devins GM, Shen J, Shapiro CM. Sleepiness is not the inverse of alertness: evidence from four sleep disorder patient groups. Exp Brain Res 2006;173:258-266. https://doi.org/10.1007/s00221-0060436-4.

53. Allen RP, Earley CJ. Restless legs syndrome: a review of clinical and pathophysiologic features. J Clin Neurophysiol 2001;18:128-147. https:// doi.org/10.1097/00004691-200103000-00004. 